

\section{DISCLAIMER}

This report was prepared as an account of work sponsored by an agency of the United States Government. Neither the United States Government nor any agency Thereof, nor any of their employees, makes any warranty, express or implied, or assumes any legal liability or responsibility for the accuracy, completeness, or usefulness of any information, apparatus, product, or process disclosed, or represents that its use would not infringe privately owned rights. Reference herein to any specific commercial product, process, or service by trade name, trademark, manufacturer, or otherwise does not necessarily constitute or imply its endorsement, recommendation, or favoring by the United States Government or any agency thereof. The views and opinions of authors expressed herein do not necessarily state or reflect those of the United States Government or any agency thereof. 


\section{DISCLAIMER}

Portions of this document may be illegible in electronic image products. Images are produced from the best available original document. 
Issued by Sandia National Laboratories, operated for the United States Department of Energy by Sandia Corporation.

NOTICE : This report was prepared as an account of work sponsored by an agency of the United States Goyernment. Neither the United States Government nor any agency thereof, 列 responsibility for the accuracy, completeness, or usefuiness of any information, apparatus, product, or process disclosed, or represents that its use would not infringe privately owned rights. Reference herein to any specific commercial product, process, or service by trade name, trademark, manufacturer, or otherwise, does not necessarily constitute or imply its endorsement, recommendation, or favoring by the United States Government, any agency there of or any of their contractors or subcontractors. The views and opinions expressed herein do not necessarily state or reflect those of the United State Government, any agency thereof or any of their contractors or subcontractors.

Printed in the United States of America Available from

National Technical Information Service

U. S. Department of Commerce

5285 Port Royal Road

Springfield, VA 22161

NTIS price codes

Printed copy: $\$ 5.00$

Microfiche copy: $A 01$ 


\section{PAGES 1 to 2 WERE INTENTIONALLY LEFT BLANK}




\title{
Mobile Digital Data Acquisition and Recording System for Geoenergy Process Monitoring and Control
}

Kenneth B. Kimball

Harvey C. Ogden

Data Systems Development Division II, 1125

Sandia National Laboratories

Albuquerque, NM 87185

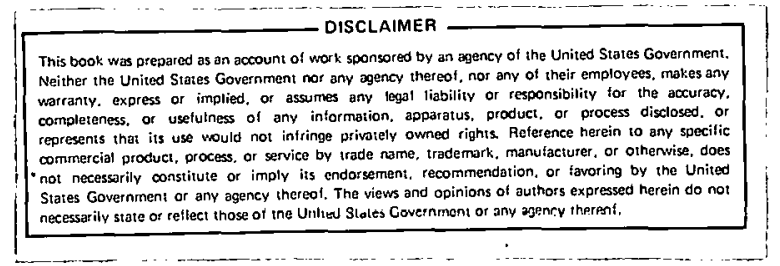

\begin{abstract}
Three mobile, general purpose data acquisition and recording systems have been built to support geoenergy field experiments. These systems were designed to record and display information from large assortments of sensors used to monitor in-situ combustion recovery or similar experiments. They provide experimenters and operations personnel with easy access to current and past data for evaluation and control of the process, and provide permanent recordings for subsequent detailed analysis. This paper briefly describes the configurations of these systems and their current capabilities.
\end{abstract}




\section{Contents}

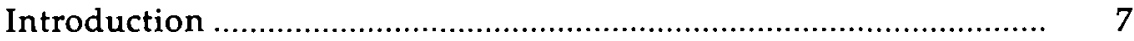

Data Acquisition System Hardware ................................................ $\quad 7$

Central Processors .......................................................................... 7

Data Display and Operator Equipment....................................... 8

Sensor and Control Interface Equipment ................................... 8

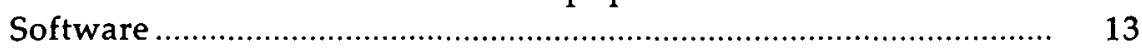

Measurand Definition File .............................................. 17

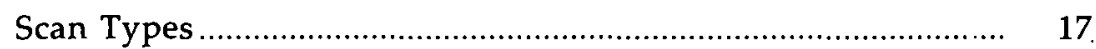

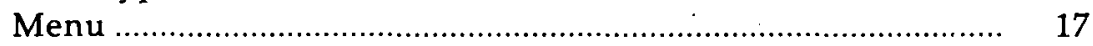

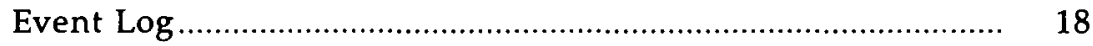

Field Support Requirements and Equipment ................................ 18

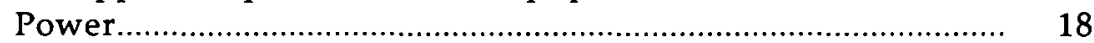

Temperature Control............................................................... 19

Test Equipment, Tools, and Equipment Maintenance................ 19

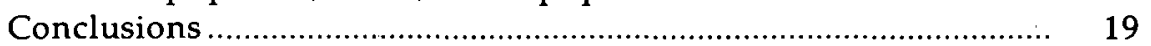

\section{Illustrations}

Figure

1 Cutaway Drawing of the B-61 Trailer Data Acquisition Sytem.

2 Block Diagram, Data Acquisition and Recording System

3 Time-History Plot of Four Temperature Sensors in a Single Instrument Well.................................................................... 14

4 Temperature Profile in One Instrument Well at a Single Time ... 14

5 Partial Listing of Temperature Data Plotted in Figure 3 .......... 15

6 Histogram of Well Temperatures as Displayed on TV Monitor... 16

7 Equipotential Contour Plot for Surface Array of Earth Resistivity Probes.

8 Time-History Plot of Some Production Well Gas Components

9 One-Line Diagram of ac Power Input Circuits............................. 18

\section{Tables}

1 General Purpose Analog Input Systems ..................................... 13

2 Data Logger Capacity .............................................................. 13 


\section{Mobile Digital Data Acquisition and Recording System for Geoenergy Process Monitoring and Control}

\section{Introduction}

Three mobile, general purpose data acquisition and recording systems have been built to support geoenergy field experiments. These systems were designed to provide:

1. Ability to acquire measurement data from a wide variety and large number of sensors.

2. Ability to organize and store data in forms readily accessible to on-site personnel and easily transferable to large scientific computers where more sophisticated processing and analysis may be done.

3. Diagnostic information on and ability to ap: ply mathematical models to physical and chemical mechanisms associated with the experiment for use in analyzing, controlling, and optimizing the process.

4. A simple user interface to allow users with little or no computer experience ready access to data with minimum supervision and without compromising system integrity, and realtime data made available to such users in the form of plots, listings, and CRT monitor displays.

5. Ready adaptability in both hardware and software to different experiment types and configurations.

The systems are housed in $10-\times 40-\mathrm{ft}$ trailers which carry Sandia identification numbers B-35, B-49, and B-61. They share the same general system design, but some hardware differences exist between them. Advantage was taken of new equipment models available as new systems were being built, and some special purpose equipment was obtained for particular experiments. Hardware and software can be transferred between systems for particular experiments. The cutaway drawing of B-61 shown in Figure 1 illustrates a typical trailer layout.

Current hardware and software capabilities of these systems are briefly summarized below. It should be noted that these systems are continually being updated and altered for particular experiments; therefore, at any given time, the precise configuration of a particular trailer may differ somewhat from that described.

\section{Data Acquisition System Hardware}

A typical system block diagram is shown in Figure 2. The heart of the system is a MODCOMP general purpose digital computer. It is interfaced to the experiment or process through a variety of analog and digital measurement and control instruments, shown to its left. An assortment of computer peripherals shown on the right provide human interfaces and permanent data recording.

\section{Central Processors}

The B- 35 and B-49 systems have MODCOMP II central processors with $128 \mathrm{~K}$ bytes of central memory and $20 \mathrm{M}$ bytes of disc memory, and use MAX III, a real-time multiuser software operating system. The B-61 system has a MODCOMP "classic" $7863 \mathrm{CPU}$ 
with $512 \mathrm{~K}$ bytes of central memory and $87 \mathrm{M}$ bytes of disc memory, and uses MAX IV, a real-time multiuser software operating system. All three systems have high speed floating point processors, direct memory $1 / O$ processors, and 16-bit word length; each is supported by two 9-track tape recorders.

\section{Data Display and Operator Equipment}

Three or more operator terminals provide means for user communications with the system. There is at least one printing terminal for logging system activity and one with graphics capability for producing data plots. Limited access by dial-up telephone line from remote terminals is available through an automatic answer MODEM. An electrostatic printer/ plotter lists data and programs and makes hard copy data plots. Two video drivers allow us to display data on TV monitors located within a few hundred metres of the trailer. Several monitors may be run in parallel on each video cable.

\section{Sensor and Control Interface Equipment}

Terminal strips along one wall of each trailer will accommodate over 1000 pairs of shielded input/ output signal wires. Five hundred twelve sets of these terminals are enclosed in isothermal "zone" boxes suitable for use as thermocouple reference junctions. A variety of signal conditioning and conversion equipment is available for processing input/ oulpul signals.

A combinatorial multiplexer* (COMUX) is used for scanning thermocouples and other low-level signals. In addition to standard sequential scanning, the COMUX selects various combinations of signal leads, shields, and reference points from multiterminal circuits. The COMUX output is measured with an integrating digital multimeter (IDMM) which will measure dc and ac voltage, current, and resistance. The COMUX and IDMM combination provide capability to make diagnostic measurements and calibration checks along with standard automatic scanning sequences. For example, measurements of sensor loop resistances, noise voltages, and circuit isolation resistances provide valuable diagnostic information for assessing sensor integrity during tield experiments.

\footnotetext{
${ }^{*}$ K. B. Kimball and C. A. Denney, COMUX: A Combinatorial Multiplexer for Diagnostic Scanning of Multiterminal

Thermocouple and Microvolt Level Circuits, SAND79-0797.
}

The COMUX and IDMM may be operated manually during experiment preparation and troubleshooting or under computer control via the IEEE-488 Standard Digital Interface for Programmable Instrumentation (GPIB). Commercial GPIB extenders make it possible to operate these units at distances up to 1000 metres from the computer using two twistedpair cables.

Three general purpose analog input systems are available to accommodate a wide variety of input signals. Table 1 summarizes their capability and the typical allocation of channels to each trailer.

Channel allocations can be changed to accommodate particular job requirements by simply inserting additional printed circuit cards.

Each channel contains a low-pass filter preceding the multiplexer switches for signal bandwidth limiting. Single- and double-pole filters with cut-off frequencies ranging from 2.8 to $740 \mathrm{~Hz}$, high voltage attenuators and a filter bypass are avallable or can be purchased to meet particular signal conditioning requirements.

The IEEE-488 GPIB readily interfares with a large number of commercially available instruments. Each bus can operate up to 15 instruments, such as frequency counters, programmable power supplies, signal generators, gas chromatographs, etc. A pair of GPIB extenders connected with two twisted shielded pair cables allow instruments to be located up to 1000 metres away. Larger separation is possible if MODEMS are used. This provides considerable versatility to meet the wide range of requirements encountered in different experiments.

A general purpose digital input/output interface subsystem (IOIS) provides a wide variety of sensing and control capabilities. It will accommodate any combination of 16 printed circuit cards that provide such functions as contact closures, contact sensing, $\mathrm{ds}$. and ac voltage outputs and inputs, alarm sensing, etc. Typically, each card provides 16 signals. A good selection of cards is available in each trailer.

A system to measure earth resistivity has been included in each trailer. Programmable power supplies and/or battery banks are used for injecting excitation currents into the earth. A group switch multiplexes up to 448 sensing electrodes into a set of 64 isolation amplifiers whose outputs are digitized by the wide range solid-state (WRSS) analog input subsystem. Seventy channels of WRSS are available for other uses when earth resistivity experiments are not being conducted.

A current or potential electrode selector (COPES) interchanges excitation and sensing functions among 16 electrodes in any desired combination. In borehole 


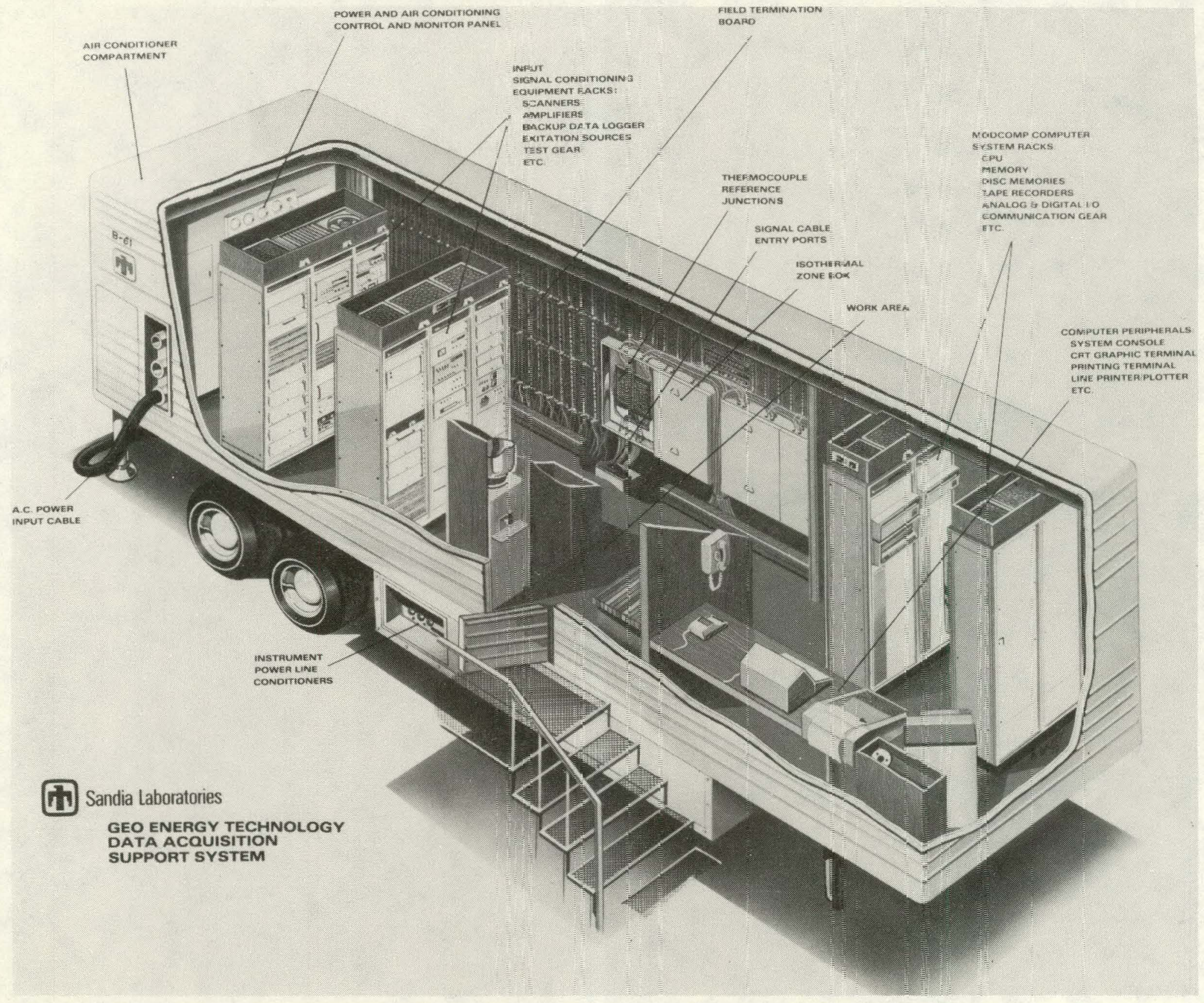




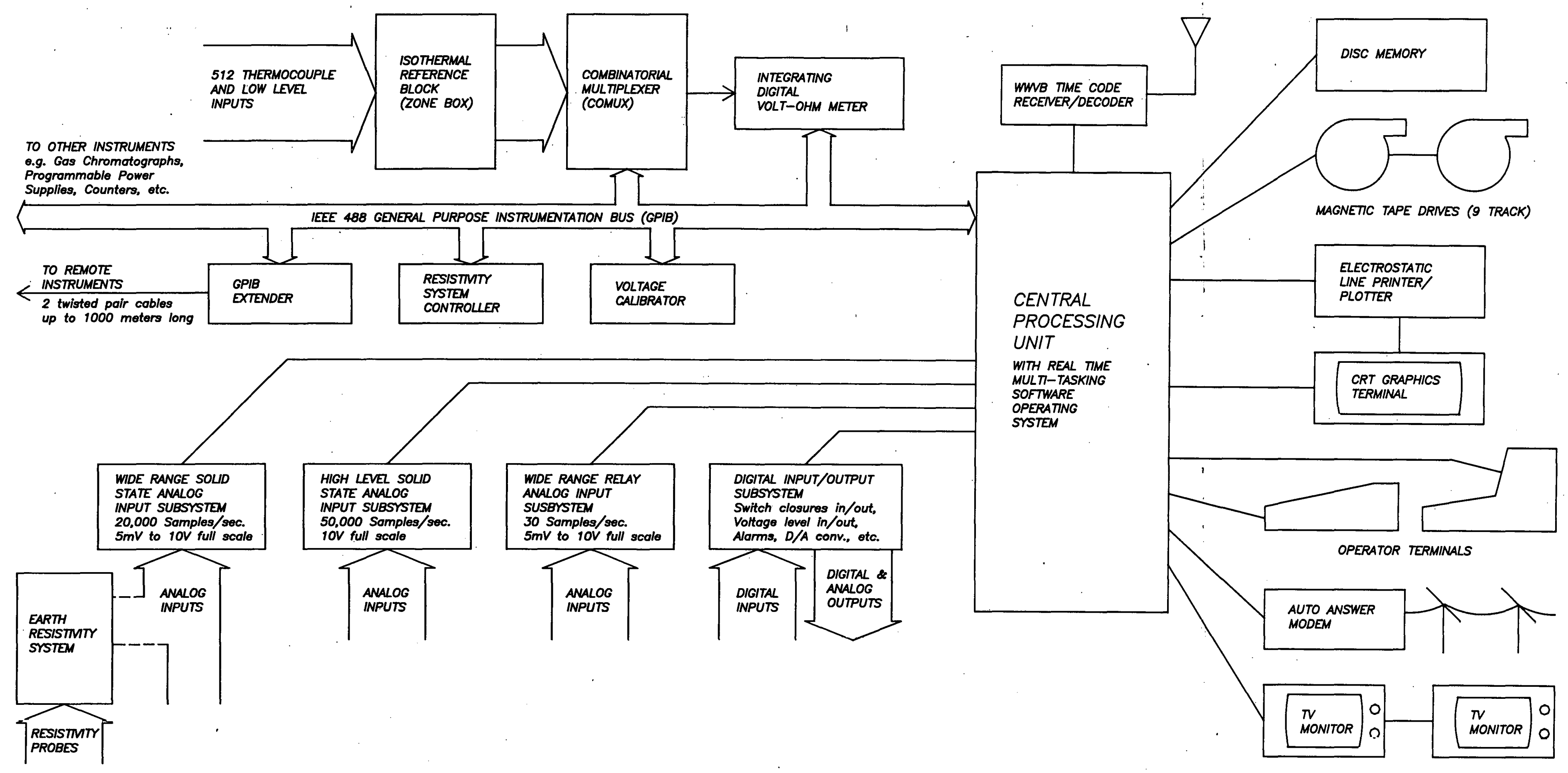


Table 1 General Purpose Analog Input Systems

Typical Number
of Channels

Expandable to

Scan Rate

(samples/s)

Max Common

Mode Voltage

Input Range

(programmable)

\section{B-35 \\ B- 49 \\ B-61}

Wide Range

Solid-State

Subsystem

\section{Wide Range \\ Relay \\ Subsystem}

96
80
96

128

20,000

$\pm 10 \mathrm{~V}$

$\pm 5 \mathrm{MV}$ to $\pm 10 \mathrm{~V}$
$0^{*}$

64

64

128

30

$\pm 200 \mathrm{~V}$

$\pm 5 \mathrm{MV}$ to $\pm 10 \mathrm{~V}$
High Level
Subsystem

16

$0^{*}$

$0^{*}$

128

50,000

$\pm 20 \mathrm{~V}$

$\pm 10 \mathrm{~V}$

* Subsystem main frame is not included in system.

arrays, this permits measurements with various effective depths of penetration. One COPES will service four boreholes containing 16 probes each.

Standard time, as broadcast by the National Bureau of Standards (NBS) over station WWVB, is used to establish a consistent and reliable time base for the system. A WWVB receiver continuously monitors and decodes the NBS signal and accurately outputs the correct time of year to within a few milliseconds. The computer system clock is set to the received time whenever the system is powered up or restarted and is periodically checked while the system is operating. This procedure alleviates the time base problems often encountered in automatic data acquisition systems operating with intermittent or noisy power lines.

A data logger, powered by an uninterruptible power supply, is provided in each trailer to back up critical data channels. This provides continuity of data through periods when the primary system is down because of power or equipment failures or for maintenance and repair. Data logger output is printed on paper tape and recorded on cassette or cartridge magnetic tape. Data logger capacity in each trailer is given in Table 2.

\section{Table 2 Data Logger Capacity}

\begin{tabular}{llc} 
Trailer & \multicolumn{1}{c}{ Model } & No. Channels \\
B-35 & Autodata 8 & 240 \\
B-49 & Fluke 2240A & 300 \\
B-61 & Fluke 2240A & 540
\end{tabular}

Rack space is available for mounting special purpose signal conditioning or other equipment that may be required for a particular experiment.

\section{Software}

The software system for the trailers has been designed to:

- Fully support the hardware

- Be as general and flexible as possible

- Have a variety of user-oriented outputs

- Have a simple user interface

Data can be brought into the system from any of the analog input subsystems, the IOIS, the IEEE-488 instrumentation bus, or the RS-232C communication ports; or it can be hand-entered via a system terminal. The data is stored on disk files to provide fast access for plotting programs, listing programs and other data analysis, and reduction programs. Periodically (usually once a day) the data is copied to magnetic tape to provide backup for the data and to allow it to be conveniently transported to other sites for alternate analysis.

The system provides the user with a variety of tools to observe the progress of the experiment and to analyze the data:

- Time-history plotting of any measurand

- Profile plots

- Contour plots

- Complete data listing capability

- Real-time monitor displays 
Figures 3 through 8 include examples of each of these outputs taken from an in-situ oil shale retorting experiment near Rock Springs, Wyoming.

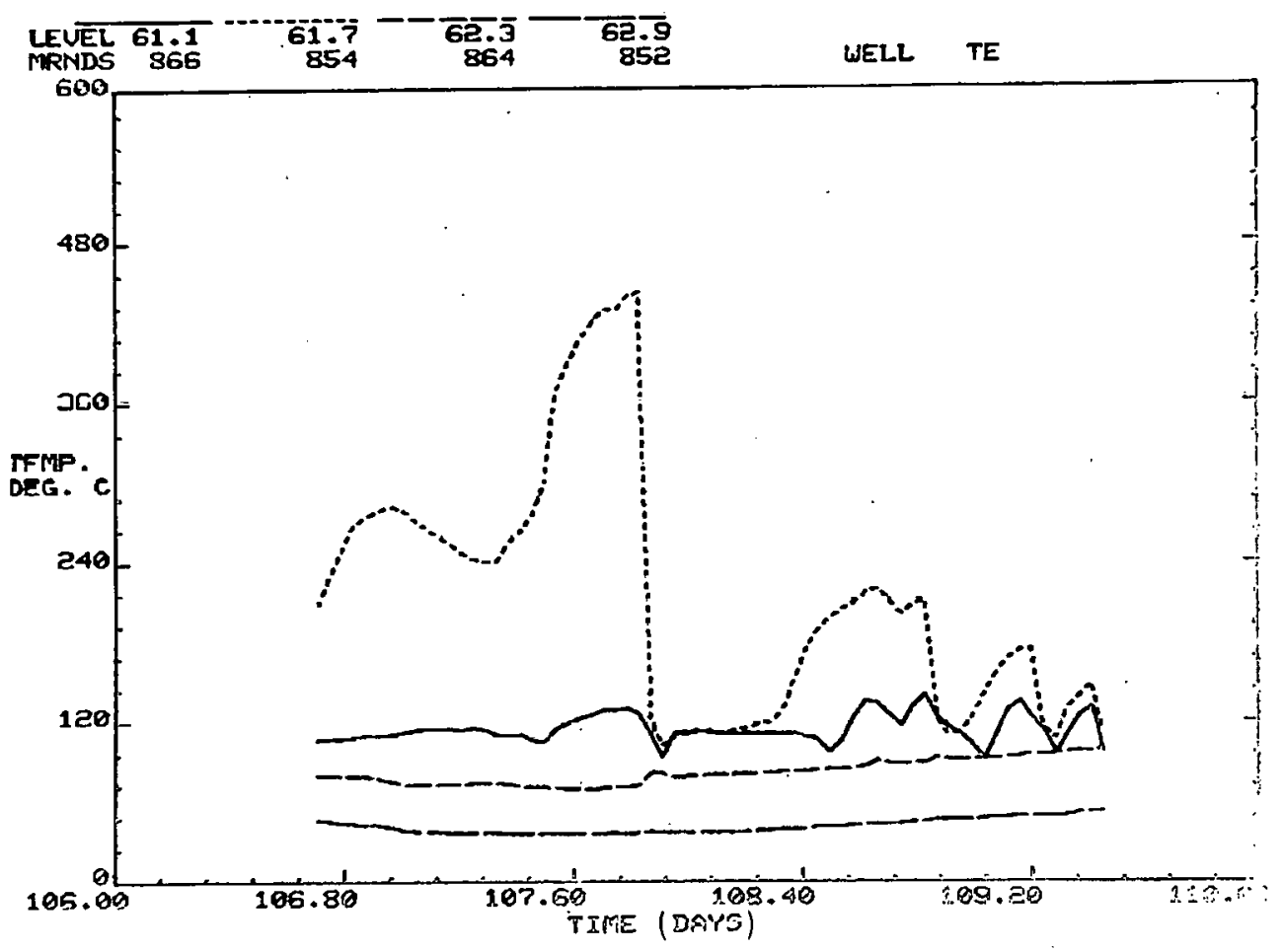

. Figure 3. Time-History Plot of Four Temperature Sensors in a Single Instrument Well

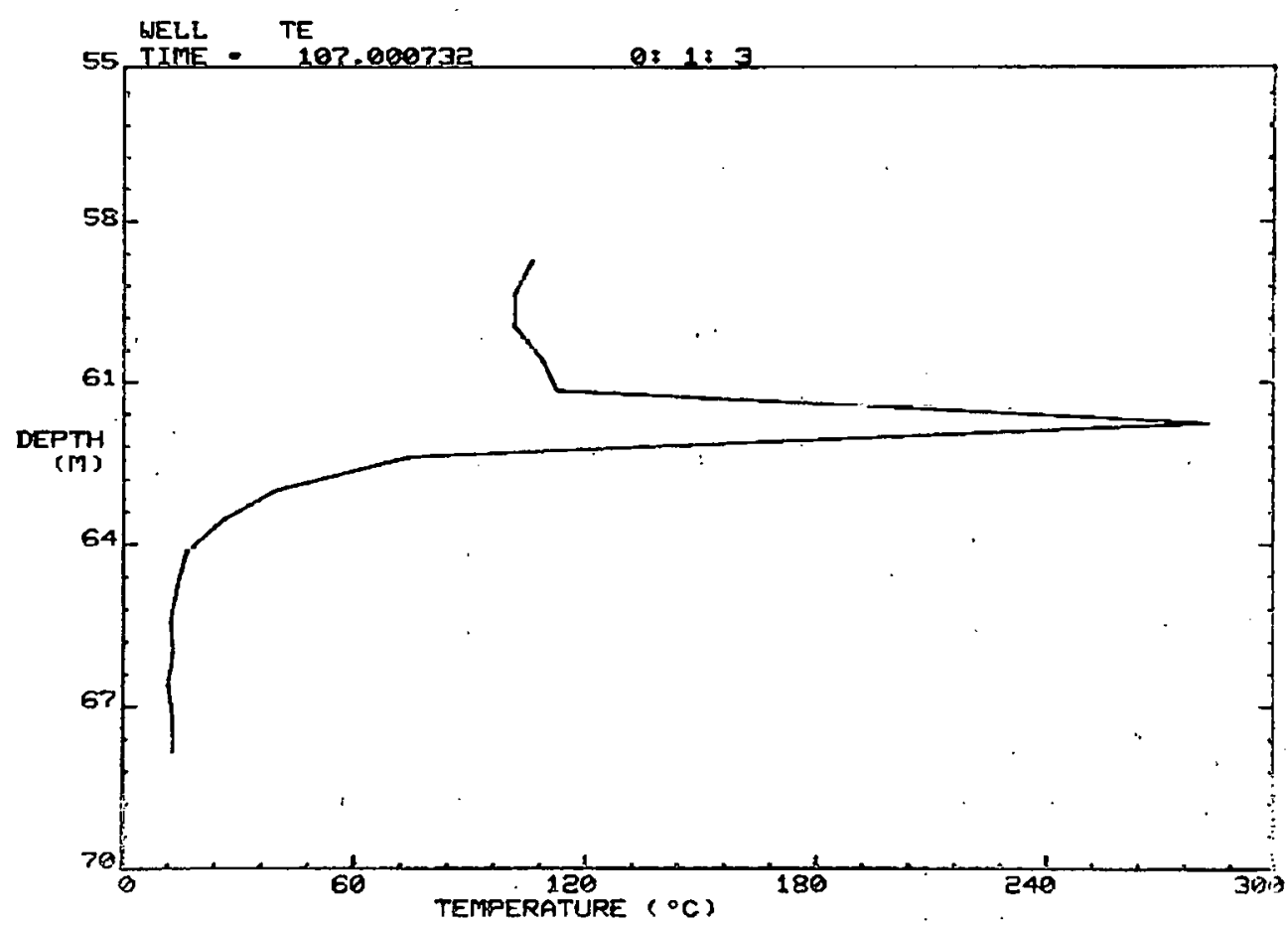

Figure 4. Temperature Profile in One Instrument Well at a Single Time 
TIME HISTORY DATA LISTING

SCAN TYPE 1

CIRCULAR FILE

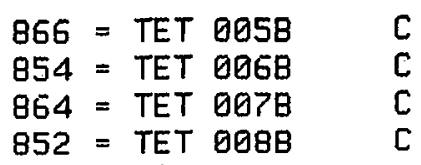

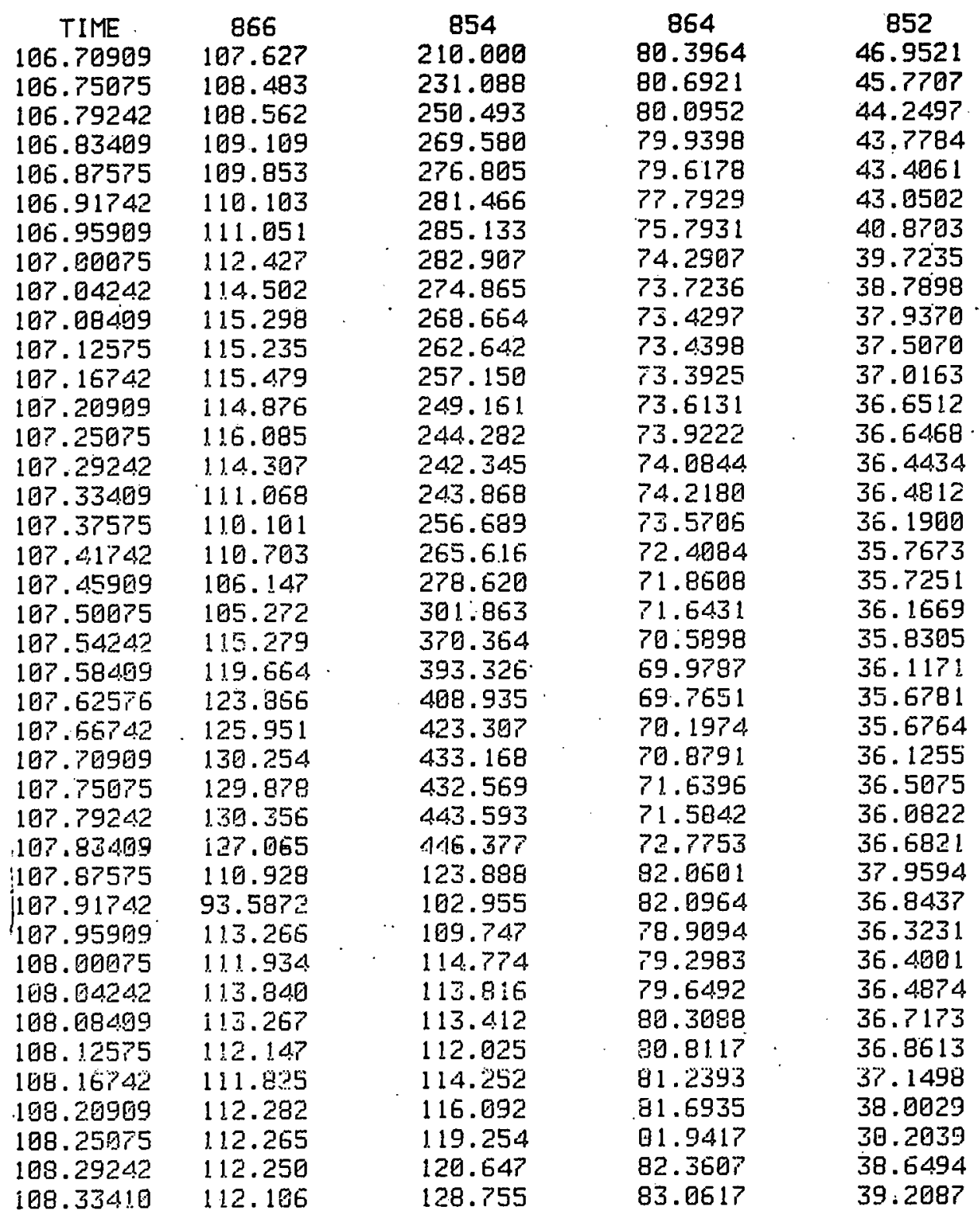

\$\$

Figure 5. Partial Listing of Temperature Data Plotted in Figure 3 


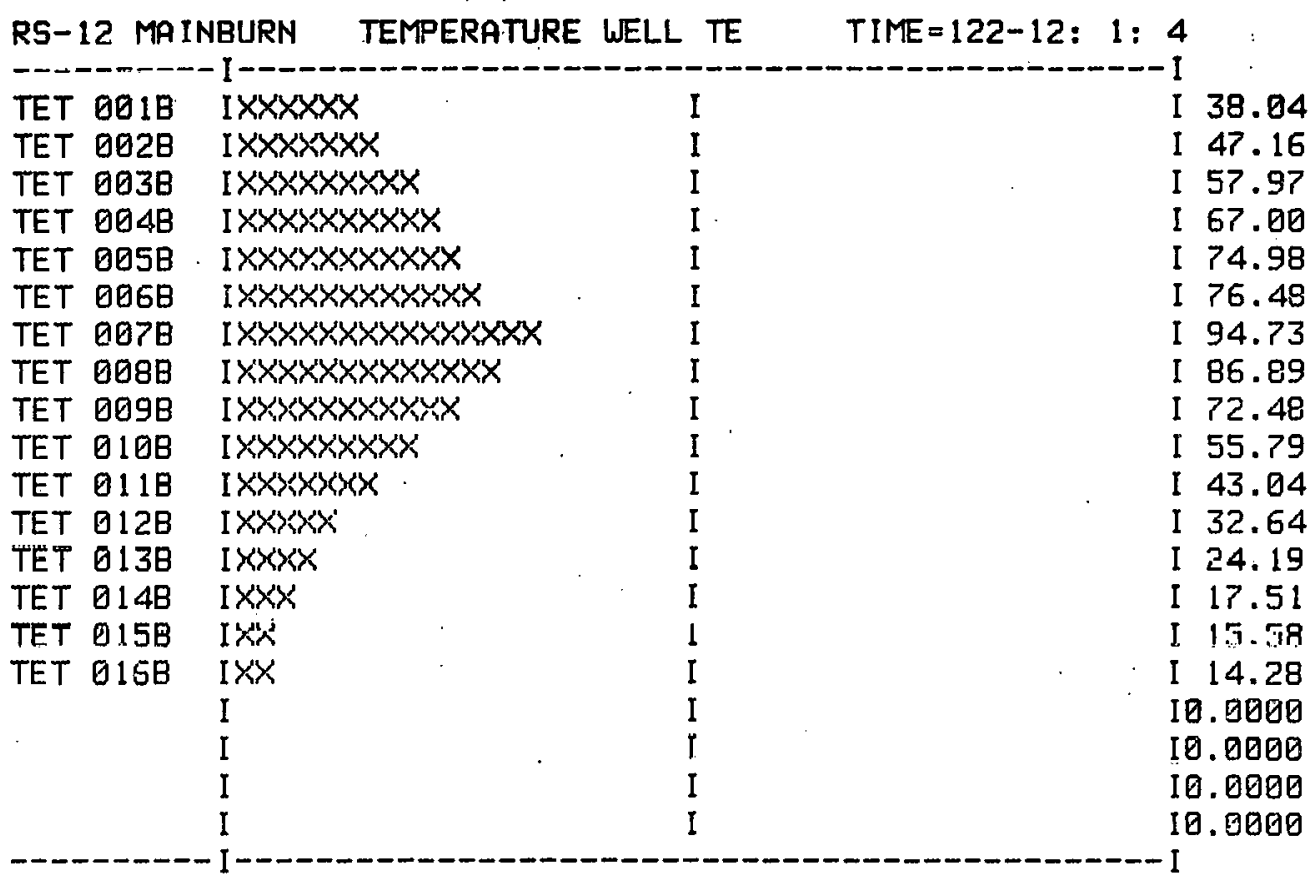

0.0300 .0

0.0300 .0

0.0300 .0

0.0300 .0

0.0300 .0

0.0300 .0

0.0300 .0

0.0300 .0

0.0300 .0

0.0300 .0

0.0300 .0

0.0300 .0

0.0300 .0

0.0 300.0

0.0300 .0

0.0300 .0

$0.0 \quad 0.0$

$0.0 \quad 0.0$

$0.0 \quad 0.0$

$0.0 \quad 0.0$

Figure 6. Histogram of Well Temperatures as Displayed on TV Monitor

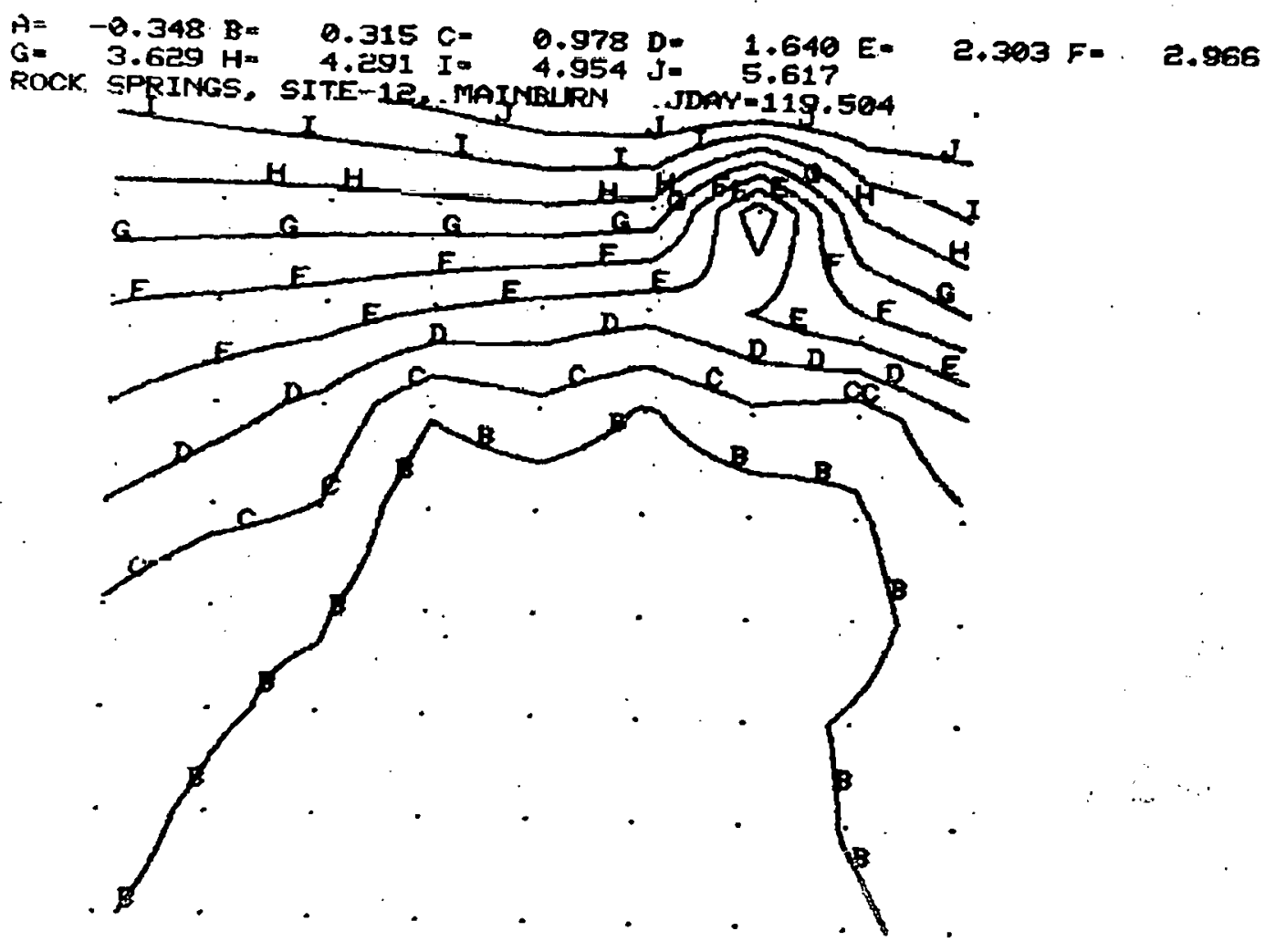

Figure 7. Equipotential Contour Plot for Surface Array of Earth Resistivity Probes 


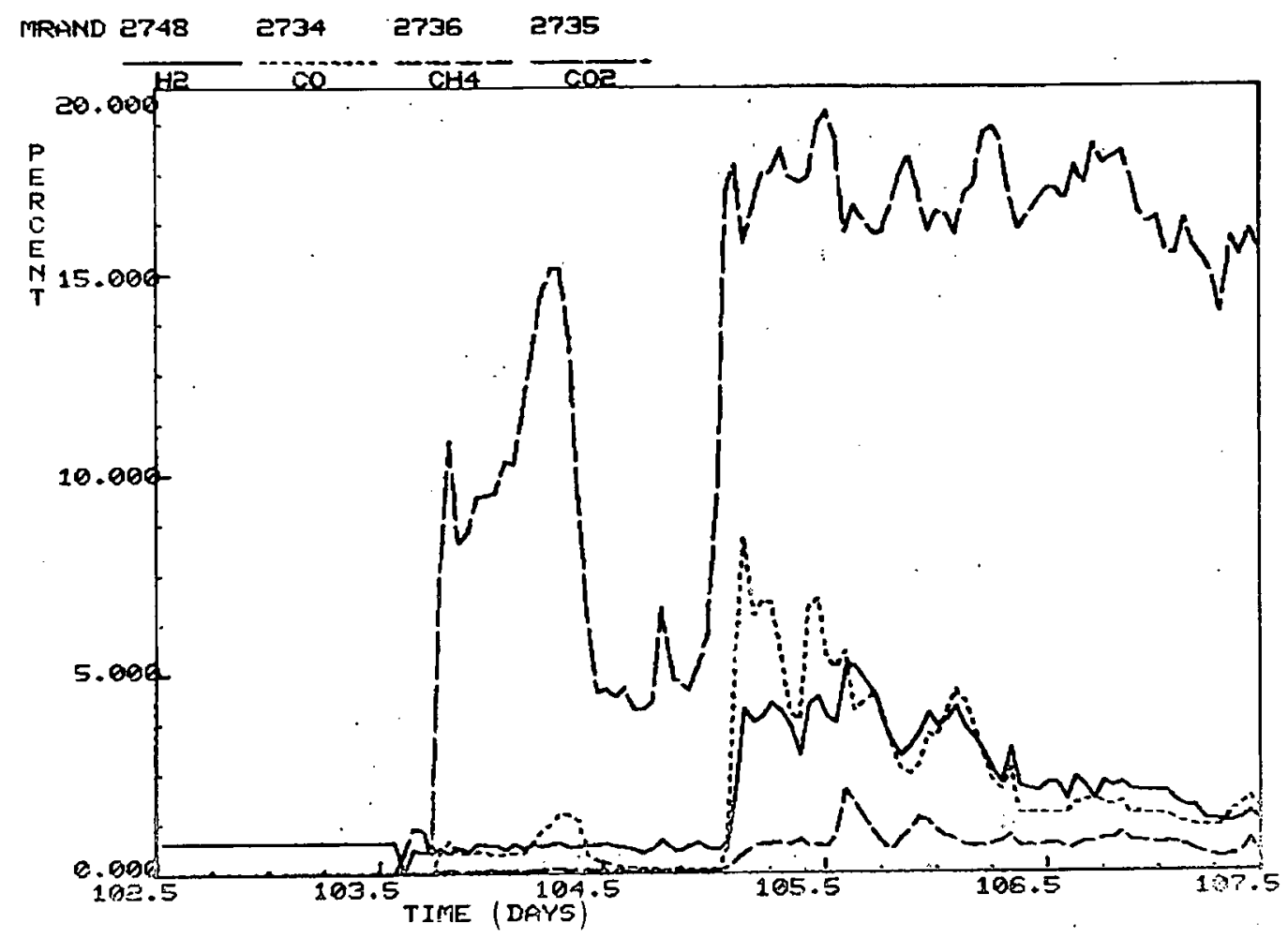

Figure 8. Time-History Plot of Some Production Well Gas Components

\section{Measurand Definition File}

In order to be as general and as flexible as possible, the system is "table driven"; that is, all the parameters that define a particular experiment are stored in a disk file called the "Measurand Definition File." This file defines all the measurements to be taken, and provides the acquisition program with the information it needs to take the data and all, other programs with the information they nced to interpret the data. This approach eliminates the need for reprogramming for every new experiment. It is the responsibility of the experimenters to provide the information necessary to create the Measurand Definition File.

\section{Scan Types}

The total set of measurands can be subdivided into 32 subsets called scan types. Each scan type is assigned its own scanning interval and has its data stored in its own disk file. Measurands may be added to or deleted from a scan type and the scanning interval changed as desired throughout the course of an experiment. This provides the flexibility required to adjust sampling rates to be consistent with process activity in regions near particular sensor groups while minimizing the volume of data to be stored. It also allows us to run multiple experiments concurrently and keep their data separated.

\section{Menu}

To make it easier for the users to access the system, it has been designed so that all system resources are accessed through a master "menu" program. That is, the resources of the system are displayed on a terminal in very general categories. The user selects a category he is interested in and another menu is displayed with specific items in this category. The user then selects one of these items and a particular system program is activated which will prompt the user for the information it needs to produce the desired output. At each step of this process the computer instructs the user about what he needs to enter next. This allows users with little or no computer experience to access the data with minimum supervision and in such a way that the integrity of the system is protected. 


\section{Event Log}

An event $\log$ is maintained in a disk file to document all activities pertinent to the experiment. Actions initiated on the computer terminals are automatically entered in the event log; e.g., changing measurands in a scan type or changing scan frequency. Other activities are manually entered by the operators; e.g., plumbing alterations or equipment modifications.

The MODCOMP computers, together with the operating systems under which all this software is run, provide considerable room for future expansion. Because of the flexibility of the "table-driven" approach, new applications can be added with a minimum of difficulty.

\section{Field Support Requirements and Equipment}

\section{Power}

Three-phase, 208-V, wye-connected power is required to operate the trailers. Utility power drain is typically 25 to $30 \mathrm{kVA}$ for operating heaters, air conditioners, lighting, etc. Instrument power drain for operating the data acquisition and computer equipment is typically 3 to $5 \mathrm{kVA}$. The trailers are wired to accommodate backup and separate instrument power sources when these are required to improve reliability and quality. A one-line diagram of the power input circuitry is shown in Figure 9.
Sensors in the automatic transfer switch monitor the voltage of the primary and secondary power sources. If an out-of-limits condition occurs in the primary source, the switch will transfer to the secondary source only if that secondary source is within limits. Switchback to the primary source can be done manually or automatically after the primary has been in-limits for a preset period of time. A diesel generator with automatic start capability may be used as the secondary power source. The transfer switch controller provides the necessary control signals to start the generator within $10 \mathrm{~s}$ after a primary power failure. The automatic power fail restart feature of the computer system will prevent any loss of data and will reinitiate any scans that were in process when a powcr interruption occurred.

An input connector and manual switch are provided to accommodate an optional independent power source for instrument power. All instrument power, regardless of the source, is passed through ac power line conditioners to remove disturbances and noise. A transient protector following the transfer switch protects against fast high-energy surges such as lightning strikes.

Provisions have been included for grounding the trailer shell and power line neutral at a single point such as a wellhead. Appropriate warning lights are included for situations where the trailer shell might be at a potential different from local ground.

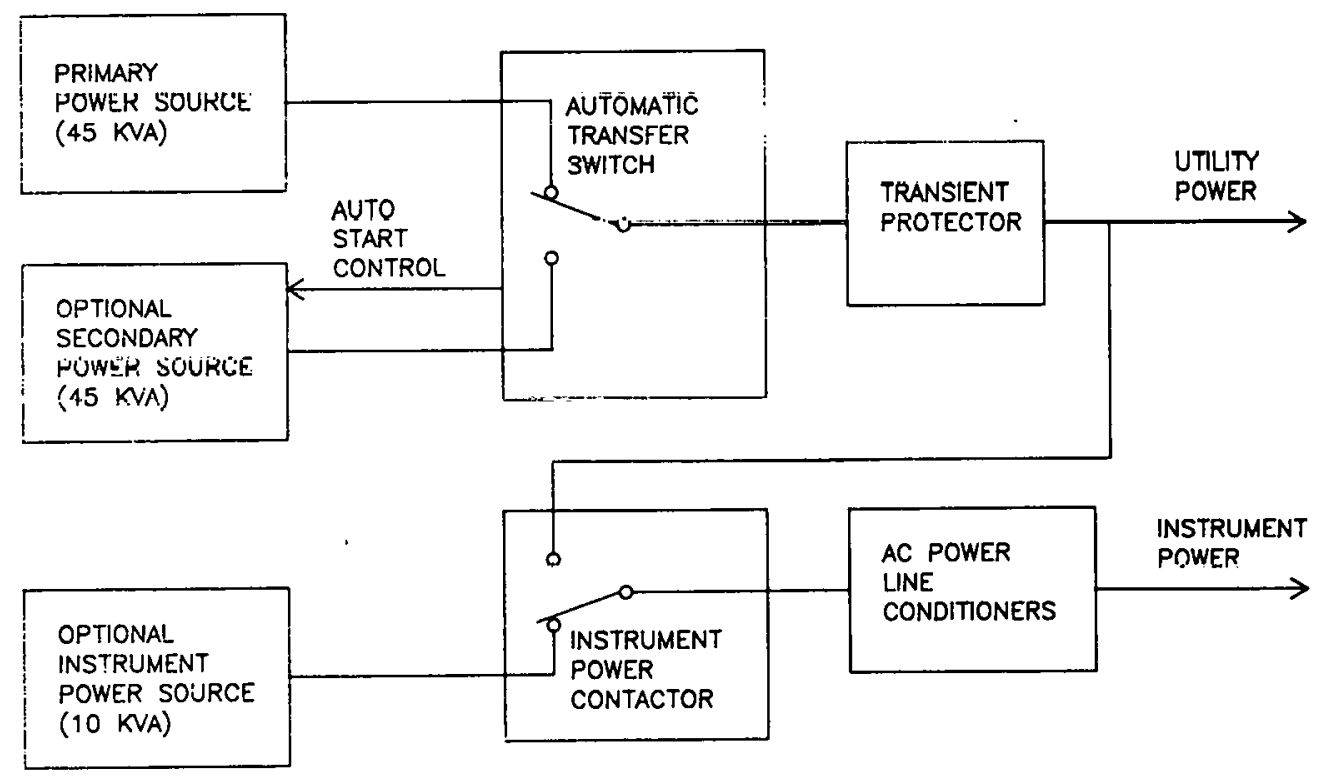

Figure 9. One-Line Diagram of ac Power Input Circuits 


\section{Temperature Control}

Two 5-ton refrigeration units and electric heaters provide temperature control for the electronic gear. Ducts in the ceiling and floor provide closed-loop circulation to the equipment racks. Each rack is equipped with a fan and adjustable louvers for regulating air flow. Rack temperature sensors are wired to local readouts for operator convenience and to the data acquistion system so they can be included in the data base for diagnostic purposes.

\section{Test Equipment, Tools, and Equipment Maintenance}

A reasonable complement of tools, test and calibration equipment, and spare parts is carried in each trailer. This allows field operations personnel to set up and maintain the experiment, and to perform minor repairs and maintenance on trailer equipment. Specialized field service technicians are called in or equipment is returned to the factory for major repairs, depending upon the urgency of the situation and the availability of backup equipment. We keep a standard full-service maintenance and repair contract with MODCOMP to service the computer equipment. This provides regular periodic preventive maintenance by qualified MODCOMP servicemen and 24-h response to remedial service calls.

\section{Conclusions}

The three mobile data acquisition systems described have been used to monitor several types of geoenergy field experiments. These systems have proven very beneficial in cataloging and recording large quantities of data and making them easily accesible for prompt on-site evaluation and control of experimental processes. System hardware and software are flexible enough to easily adapt to a wide variety of sensor types and experiment configurations, and provide room for future expañsion. Software is transportable among the three systems; so features added for each new application benefit all three systems. Therefore, the capabilities of these systems and the convenience of using them are constantly improving. 


\section{DISTRIBUTION:}

TID-4500-R68 UC-37 (175)

Assistant Secretary

for Fossil Energy

Mail Stop B-126

Washington, DC 20545

Attn: G. Fumich, Jr.

W. B. Schmidt

US Department of Energy

Assistant Secretary for Coal

Technology

Mail Stop E-378

Washington, DC. 20545

Attn: A. Liccardi, Acting Deputy

US Department of Energy

Office of Deputy Assistant Secretary

fur Oil, Gas and Shalc Technology

Mail Stop D-107

Washington, DC 20545

Attn: M. Adams
L. M. Durman
B. Harney
J. W. Ramsey
A. M. Hartstein
J. B. Smith
P. R. Wieber
H. E. Thomas
E. L. Burwell
R. W. Markley
D. Uthis
J. W. Watkins
J. J. Stnsuır

US Department of Energy

Division of Planning \& Systems Engr.

Room C-164

Washington, DC 20545

Attn: J. T. Bartis, Acting Director

US Department of Energy

Energy Research and Technology Division

Albuquerque Operations Office

Albuquerque, NM 87185

Attn: D. Krenz

US Department of Energy

Denver Projects Office

P. O. Box 26500

1 n75 Snuth Yukon. Suite 211

Lakewood, CO 80266

Attn: W. Noll

US Department of Energy/BETC

P. O. Box 1398

Bartlesville, OK 74003

Attn: H. Johnson
US Department of Energy

Energy Research and Technology Division

P. O. Box 26500

1075 South Yukon, Suite 211

Lakewood, CO 80226

Attn: W. Noll

Laramie Energy Technology Center

P. O. Box 3395, University Station

Laramie, WY 82071

Attn: R. J. Jiacoletti

H. J. Weber

W. E. Little

B. C. Suddeth

L. P. Jackson

D. R. Johnson

A. E. Harak

R. E. Püulson

A. W. Decora

T. C. Bartke

US Department of Energy/METC

Box 880

Collins Ferry Road

Morgantown, WY 26505

Attn: A. A. Pitrolo

L. A. Schrider

J. W. Martin

A. Liberatưré

(4)

US Department of Energy/PETC

Office of Advanced Research Technology

4800 Forbec $\Lambda$ venue

Pllsbugli, rA 15213.

Attn: I. Wender
Los Alamos National Scientific Laboratory

I.ns Alamos. New Mexiço 87545

Attn: W. J. Carter, DAD/AES, MS 329

T. S. Adams, G-6, MS 665

W. A. Morris, G-4, MS 586

J. N. Johnson, T-4, MS 214

C. L. Edwards, G-2, MS 978

Lawrence Livermore National Laboratory P. O. Box 808

Livermore, CA 94550

Attn: A. E. Lewis

K. Street, L-13

R. J. Lytle, L-156

D. R. Stephens, L-437

S. J. Spitaro, L-218

US Department of the Interior

US Bureau of Mines

Washington, DC 20240

Attn: T. Falkie, Director

(5) 
DISTRIBUTION: (Cont)

US Bureau of Mines - Twin Cities (2)

P. O. Box 1660

Twin Cities Airport, MN 55111

Attn: R. Thill

S. Demou

Electric Power Research Institute 3412 Hillview Avenue

Palo Alto, CA 94304

Attn: R. Balzhiser

Washington Irrigation and

Development Company

1015 Big Hanaford Road

Centralia, WA 98513

Attn: R. A. Paul

Office of the Governor

Legislature Building

Olympia, WA 98405

Attn: B. McClelland Special Assistant

Science Applications, Inc. (2)

1546 Cole Blvd.

Suite 210

Golden, CO 80401

Attn: H. E. McCarthy

G. B. French

Blastmasters, Inc.

325 Beverly Avenue

San Leandro, CA 94577

Attn: K. Britton

Rio Blanco Oil Shale Co.

9725 E. Hampden Avenue

Denver, C.O 802.31

Attn: J. Knepper

Science Applications, Inc.

P. O. Box 273

Steamboat Springs, CO 80477

Attn: C. Young

Occidental Oil Shale, Inc. (9)

751 Horizon Drive

Box 2687

Grand Junction, CO 81501

Attn: W. McDermott

K. Ellington

R. Nelson

G. Gruber

T. Ricketts

B. Romig

W. Karwoski

J. Feinmin

R. Bloom
U S Department of Energy/LETC

2781 Crossroads Blvd, Rm. 110

Grand Junction, CO 51501

Attn: J. Virgona

Equity Oil Company

$10 \mathrm{~W}$. Third South

Suite 806

Salt Lake City, UT 84101

Attn: P. M. Dougan

Geokinetics, Inc.

288 Buchanan Field Rd.

Concord, CA 94520

Attn: M. Lekas

US Department of Interior (2)

Area Oil Shale Office

131 North 6th, Suite 300

Grand Junction, CO 81501

Attn: P. Rutledge

L. Barker

Rocky Mountain Energy Co.

Lakeside National Bank Bldg.

4707 Harlan Street

Devner, CO 80212

Attn: T. I. Sharps

The Aerospace Corporation

2350 East El Segundo Blvd.

El Segundo, CA 90009

Attn: G. F. Kuncir

Geokinetics Inc.

$\mathrm{C} / \mathrm{O} 582 \mathrm{~N}$. Vernal Avenue

Vernal, UT 84078

Attn: 'J. J.ekas

US Department of Energy

Carbondale Mining Technology Center

P. O. Box 2587

Carbondale, IL 62901

Attn: T. Ziegler

1000 G. A. Fowler

1100 C. D. Broyles

1110 J. D. Plimpton

1111 J. R. Banister

1111 C. R. Mehl

1116 S. R. Dolce

1116 R. P. Reed

1120 T. L. Pace

1121 R. L. Rutter

1123 B. C. Benjamin

1123 R. W. Donohoe

1124 J. W. Wistor

1124 J. W. Allen 
DISTRIBUTION: (Cont)

\section{C. O. Dumstra}

1125 G. L. Ogle

1125 J. A. Begeler

1125 C. A. Denney

1125 K. B. Kimball

1125 R. J. Longoria

1125 J. T. McIlmoyle

1125 H. C. Ogden

(10)

1126 H. B. Austin

1126 G. J. Hansen

1130 H. E. Vincy

1131 B. G. Edwards

1132 A. Church

1133 R. D. Statler

1137 G. L. Miller

1170 S. A. Moore

3151 A. A. McConnel

4700 J. H. Scott

4710 G. E. Brandvold

4720 V. L. Dugan

4730 H. M. Stoller

4732 D. A. Northrop

4733 C. L. Schuster

4734 A. L. Stevcus

4734 G. S. Davidson

4734 P. J. Hommert

4734 P. C. Kaestner

4734 K. K. Búade

4737 B. E. Bader

47.37 L. C. Bartel

47.37 R. R. Neel

4737 R. L. Parrish

4738 R. L. Fox

4738 A. J. Mulac

4740 R. K. Traeger

8266 E. A. Aas

3141 T. I.. Werner

3151 W. L. Garner

For: DOE/TIC (Unlimited Release) 


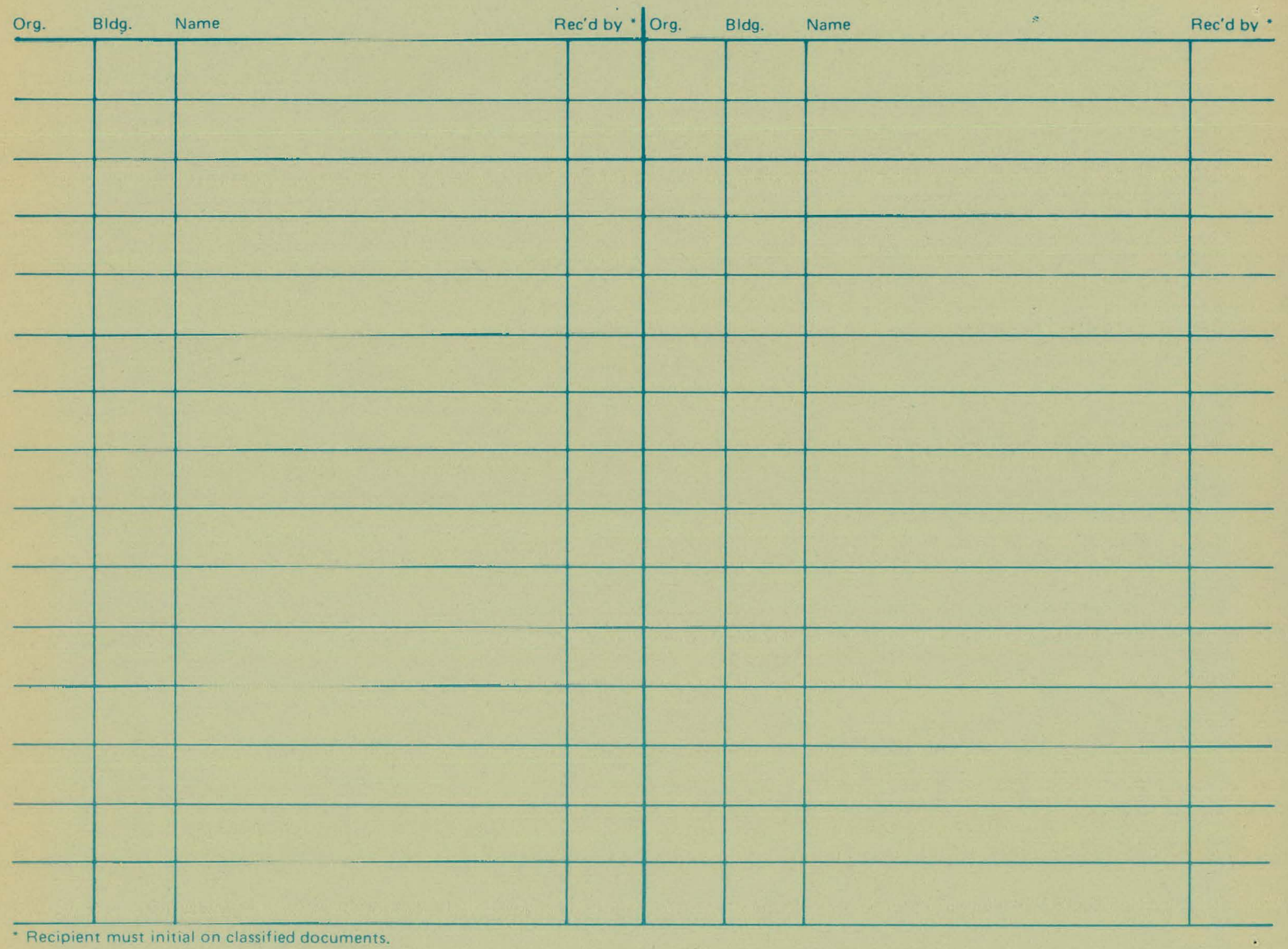

